\title{
The influence of Indian Ocean atmospheric circulation on Warm Pool hydroclimate during the Holocene epoch
}

\author{
J. E. Tierney, ${ }^{1}$ D. W. Oppo, ${ }^{1}$ A. N. LeGrande, ${ }^{2}$ Y. Huang, ${ }^{3}$ Y. Rosenthal, ${ }^{4}$ \\ and B. K. Linsley ${ }^{5}$ \\ Received 4 May 2012; revised 30 August 2012; accepted 30 August 2012; published 4 October 2012.
}

[1] Existing paleoclimate data suggest a complex evolution of hydroclimate within the Indo-Pacific Warm Pool (IPWP) during the Holocene epoch. Here we introduce a new leaf wax isotope record from Sulawesi, Indonesia and compare proxy water isotope data with ocean-atmosphere general circulation model (OAGCM) simulations to identify mechanisms influencing Holocene IPWP hydroclimate. Modeling simulations suggest that orbital forcing causes heterogenous changes in precipitation across the IPWP on a seasonal basis that may account for the differences in time-evolution of the proxy data at respective sites. Both the proxies and simulations suggest that precipitation variability during the September-November (SON) season is important for hydroclimate in Borneo. The preëminence of the SON season suggests that a seasonally lagged relationship between the Indian monsoon and Indian Ocean Walker circulation influences IPWP hydroclimatic variability during the Holocene.

Citation: Tierney, J. E., D. W. Oppo, A. N. LeGrande, Y. Huang, Y. Rosenthal, and B. K. Linsley (2012), The influence of Indian Ocean atmospheric circulation on Warm Pool hydroclimate during the Holocene epoch, J. Geophys. Res., 117, D19108, doi:10.1029/2012JD018060.

\section{Introduction}

[2] Variability in the hydrological cycle within the IndoPacific Warm Pool (IPWP) is an important component of the global climate system: perturbations in deep tropical convection reverberate through oceanic and atmospheric teleconnections and affect both tropical and extratropical climates [e.g., Ropelewski and Halpert, 1987]. Many uncertainties remain regarding the dynamics of IPWP hydroclimate, including the response of Indo-Pacific Walker circulation to both past and future global temperature change [Vecchi et al., 2006; Karnauskas et al., 2009; DiNezio et al., 2010, 2011]. Paleoclimate investigations that use both proxy data and modeling simulations provide an opportunity to improve our understanding of the hydrological cycle in the IPWP: by studying the response of IPWP hydroclimate to large, known climate forcings in the past - such as changes in the Earth's

\footnotetext{
${ }^{1}$ Department of Geology and Geophysics, Woods Hole Oceanographic Institution, Woods Hole, Massachusetts, USA.

${ }^{2}$ NASA Goddard Institute for Space Studies and Center for Climate Systems Research, Columbia University, New York, New York, USA.

${ }^{3}$ Geological Sciences, Brown University, Providence, Rhode Island, USA.

${ }^{4}$ Institute of Marine and Coastal Sciences and Department of Earth and Planetary Sciences, Rutgers, State University of New Jersey, New Brunswick, New Jersey, USA.

${ }^{5}$ Lamont-Doherty Earth Observatory, Columbia University, Palisades, New York, USA.

Corresponding author: J. E. Tierney, Department of Geology and Geophysics, Woods Hole Oceanographic Institution, 360 Woods Hole Rd., Woods Hole, MA 02543, USA. (tierney@whoi.edu)

(C)2012. American Geophysical Union. All Rights Reserved. 0148-0227/12/2012JD018060
}

orbit - it is possible to both assess our ability to correctly simulate tropical climates and identify mechanisms that govern IPWP climate response to external forcing.

[3] Paleoclimate archives that record water isotopes are useful tracers for IPWP hydroclimate, as water isotopes in the deep tropics track the amount of regional rainfall as well as synoptic-scale convective behavior [LeGrande and Schmidt, 2009; Lewis et al., 2010; Pausata et al., 2011; Tierney et al., 2011]. To date, there are two speleothem-based records of the oxygen isotopic composition of precipitation within the IPWP: one from Borneo, Malaysia [Partin et al., 2007] and another from Flores, Indonesia [Griffiths et al., 2009]. The two records depict markedly different trends in hydroclimate since the last deglaciation, suggesting regional heterogeneity within the IPWP that begs explanation. Partin et al. [2007] and Griffiths et al. [2009, 2010a] speculated that a mixture of forcing mechanisms - the influence of Earth's precession on deep convection in the IPWP, the position of the Inter-Tropical Convergence Zone (ITCZ) and rising sea levels (for the earliest Holocene) - might explain the observed patterns. Any of these mechanisms is plausible, but none have been tested against general circulation model experiments.

[4] Here we add a third IPWP isotopic record from offshore Sulawesi, Indonesia, a site that sits precisely between Borneo and Flores (Figure 1). We use a different isotopic archive - the hydrogen isotopic composition of leaf waxes $\left(\delta \mathrm{D}_{\text {wax }}\right)$ deposited in a marine sediment core - to reconstruct central IPWP hydroclimate for the last 15,000 years. Using isotopic information from three locations in the IPWP, we compare the proxy data to simulations conducted with coupled ocean-atmosphere general circulation models 


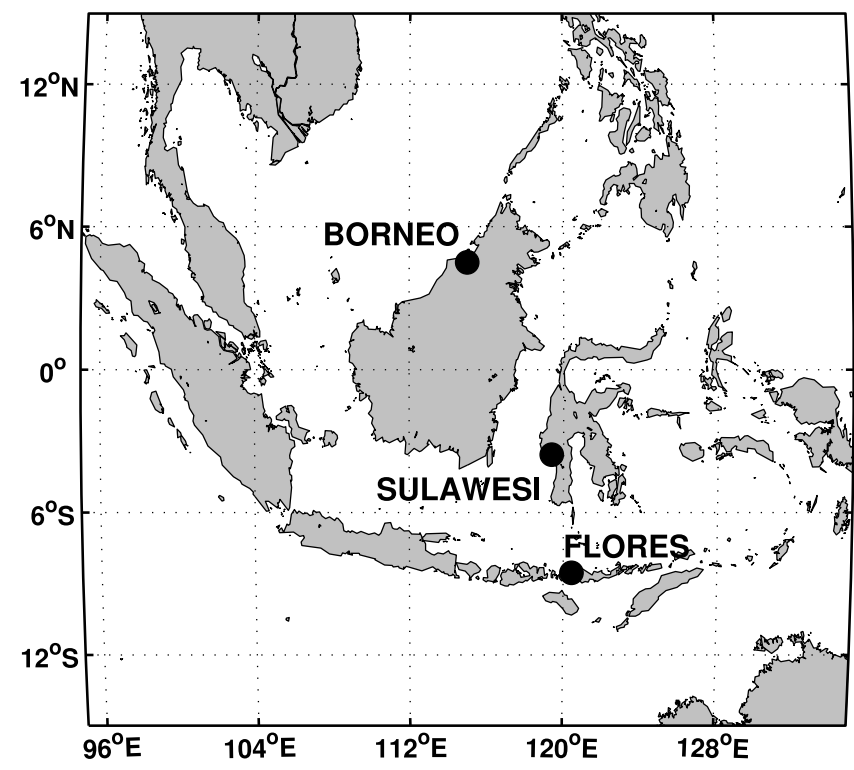

Figure 1. Locations of the three proxy sites discussed in the main text: speleothem $\delta^{18} \mathrm{O}$ from northwestern Borneo [Partin et al., 2007], sedimentary $\delta \mathrm{D}_{\text {wax }}$ from offshore Sulawesi (this study) and speleothem calcite and inclusion $\delta^{18} \mathrm{O}$ from the island of Flores [Griffiths et al., 2009, 2010b].

(OAGCMs), including the mid-Holocene (6K) simulations conducted as part of the Paleoclimate Intercomparison Project Phase II (PMIP2) and Holocene timeslice simulations conducted with the fully coupled, isotope-enabled Goddard Institute for Space Studies (GISS) ModelE-R. Using the proxy and model data in tandem, we discuss the mechanisms influencing IPWP hydroclimate and water isotopes during the Holocene epoch.

\section{Methods}

\subsection{Proxy Data}

[5] We measured the hydrogen isotopic composition of leaf waxes $\left(\delta \mathrm{D}_{\text {wax }}\right)$ in marine sediment core BJ8-03-70GGC $\left(3.566^{\circ} \mathrm{S}, 119.383^{\circ} \mathrm{E}, 482\right.$ meters water depth), located $12 \mathrm{~km}$ off the southwest shore of Sulawesi in the Makassar Strait (Figure 1). Thirteen radiocarbon dates constrain the depthage model for core 70GGC (Table 1) which is also described in Linsley et al. [2010] and Gibbons [2012]. The age model is based on a linear interpolation of the depth-age relationship between calibrated dates with the additional assumption that the top of the core is equivalent to $0 \mathrm{yr}$ BP. Core $70 \mathrm{GGC}$ was sampled every $\sim 100$ years downcore, with somewhat higher resolution during the middle Holocene (near $4 \mathrm{ka}$ ) and the Younger Dryas chronozone (12.7-11.5 ka). $\delta \mathrm{D}_{\text {wax }}$ analyses were conducted as previously described in Tierney et al. [2010]. Briefly, freeze-dried sediments were extracted with a solvent mixture of dichloromethane:methanol $(9: 1, \mathrm{v} / \mathrm{v})$ using an Accelerated Solvent Extractor. Leaf waxes were purified from the resulting total lipid extract via $\mathrm{NH}_{2}$ column chromatography, methylated with methanol of a known isotopic composition, and then further purified via silica gel chromatography. The $\mathrm{C}_{30}$ fatty acid was analyzed in triplicate for its hydrogen isotopic composition via gas chromatographyisotope ratio monitoring-mass spectrometry (GC-IR-MS), using a Thermo Delta XL mass spectrometer at Brown University. $\mathrm{H}_{2}$ standard gas calibrated to VSMOW was injected three times before and after the sample lipid peaks as an internal standard. In addition, an external fatty acid methyl ester (FAME) standard of known isotopic composition was run every nine injections to monitor drift. Isotopic values were corrected for the added methyl group. Results presented here are triplicate means, and average triplicate standard error was $0.7 \%$.

[6] $\delta \mathrm{D}_{\text {wax }}$ is an emerging proxy for the isotopic composition of precipitation and has been widely applied in tropical settings [e.g., Schefuß et al., 2005; Tierney et al., 2008], including at a nearby core site from the Makassar Strait [Tierney et al., 2010]. However, changes in wax source, including changes in vegetation or biomes through time, can complicate its fidelity as a recorder of the isotopes of precipitation [Sachse et al., 2012, and references therein]. With regards to the geographic source of the leaf waxes, given the humid (precipitation rates of 2-3 m/yr) tropical forest environment of southern Sulawesi, the proximity of the core site to the shore (12 km, Figure 1), and the high accumulation rates along the Sulawesi margin attributable to terrestrial

Table 1. Raw and Calibrated Planktonic Foraminifera ${ }^{14} \mathrm{C}$ Data for Core $70 \mathrm{GGC}{ }^{\mathrm{a}}$

\begin{tabular}{|c|c|c|c|c|c|c|c|}
\hline $\begin{array}{l}\text { Accession } \\
\text { Number }\end{array}$ & Species & $\begin{array}{c}\text { Depth } \\
(\mathrm{cm})\end{array}$ & ${ }^{14} \mathrm{C}$ Year & $1 \sigma$ & $\begin{array}{c}\text { Median Year } \\
\text { BP }\end{array}$ & Lower $1 \sigma$ & Upper $1 \sigma$ \\
\hline OS-45435 & G. ruber \& G. sacculifer & 63.5 & 1310 & 30 & 853 & 901 & 816 \\
\hline OS-54152 & G. ruber \& mixed planktonics & 104 & 2750 & 50 & 2472 & 2540 & 2352 \\
\hline OS-54153 & G. ruber \& mixed planktonics & 176 & 4240 & 50 & 4341 & 4413 & 4269 \\
\hline OS-60747 & G. ruber \& mixed planktonics & 201.5 & 4850 & 40 & 5155 & 5245 & 5079 \\
\hline OS-60750 & G. ruber \& mixed planktonics & 241.5 & 5410 & 35 & 5789 & 5847 & 5737 \\
\hline OS-54154 & G. ruber \& mixed planktonics & 280 & 6160 & 60 & 6594 & 6666 & 6513 \\
\hline OS-60737 & G. ruber \& mixed planktonics & 320.5 & 7190 & 45 & 7653 & 7695 & 7598 \\
\hline OS-70826 & mixed planktonics & 330.5 & 8080 & 40 & 8538 & 8589 & 8481 \\
\hline OS-70827 & mixed planktonics & 340.5 & 8700 & 45 & 9380 & 9438 & 9325 \\
\hline OS-70828 & mixed planktonics & 350.5 & 9210 & 45 & 10030 & 10124 & 9954 \\
\hline OS-60748 & G. ruber \& mixed planktonics & 361.5 & 10250 & 40 & 11223 & 11251 & 11187 \\
\hline OS-65581 & mixed planktonics & 393.5 & 12550 & 50 & 13990 & 14064 & 13898 \\
\hline OS-45436 & G. ruber \& G. sacculifer & 405.5 & 12900 & 45 & 14649 & 14934 & 14257 \\
\hline
\end{tabular}

${ }^{\mathrm{a}}$ From Linsley et al. [2010] and Gibbons [2012]. The ${ }^{14} \mathrm{C}$ ages were calibrated with the Marine09 curve using Calib 6.0 [Reimer et al., 2009] with $\Delta \mathrm{R}=0$. Depth-age pairs were linearly interpolated to every $\mathrm{cm}$ between dated intervals to form an age model, with the additional assumption that the coretop corresponds to $0 \mathrm{yr} \mathrm{BP}$. 

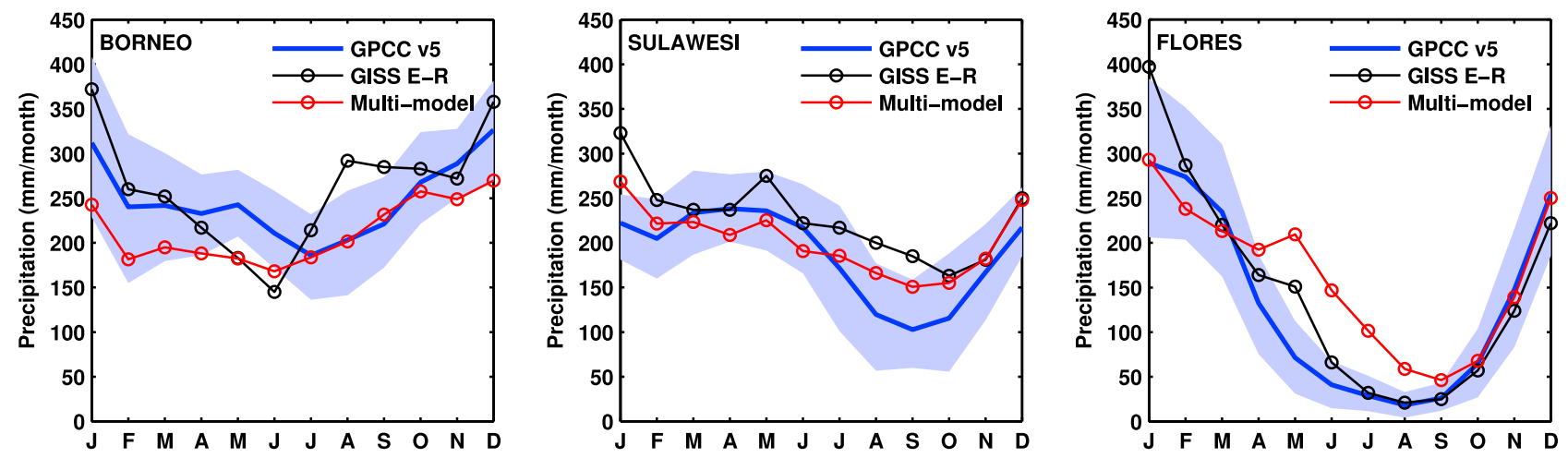

Figure 2. Observed and simulated seasonal cycles of precipitation for the Borneo, Sulawesi, and Flores sites (Figure 1). Blue lines represent the observed mean seasonal cycle of precipitation from the Global Precipitation Climatology Centre (GPCC) v5 gridded precipitation product (http://gpcc.dwd.de) [Rudolf et al., 2011], shading indicates the $68 \%$ confidence intervals. Black lines represent GISS ModelE-R simulated precipitation from the control experiment $(0 \mathrm{~K})$. Red lines represents the simulated multimodel mean of 11 PMIP2 OAGCMs. For the simulated data, values are the mean of gridcells spanning $2-6^{\circ} \mathrm{N}$, $112.5-117.5^{\circ} \mathrm{E}$ (for northern Borneo), $2-6^{\circ} \mathrm{S}, 117.5-122.5^{\circ} \mathrm{E}$ (for Sulawesi) and $10^{\circ} \mathrm{S}, 117.5-122.5^{\circ} \mathrm{E}$ (for Flores).

input (40-100 cm/ka [Oppo et al., 2009; Linsley et al., 2010]) we assume that the waxes at Site 70GGC have always been locally derived from southern Sulawesi and predominantly transported by fluvial processes. Vegetation changes through time are a greater concern as pollen evidence from northern Sulawesi indicates expansion of grasslands during the deglacial period [Dam et al., 2001]. Based on the apparent fractionation of studied grasses [Sachse et al., 2012], the effect of having grasses contribute proportionally more to the $\delta \mathrm{D}_{\text {wax }}$ signal during the deglaciation would be to attenuate the magnitude of the primary water isotope signal. From this perspective, the deglacial changes in $\delta \mathrm{D}_{\text {wax }}$ can be considered a minimum estimate. At around $10 \mathrm{ka}$, a forested woodland similar to today's became established on Sulawesi [Dam et al., 2001] and lower-resolution analyses of the carbon isotopic composition of leaf waxes in 70GGC indicate variability of less than 3\%o (J. Saenz et al., manuscript in preparation, 2012) indicating a relatively stable Holocene landscape. These data suggest that $\delta \mathrm{D}_{\operatorname{wax}}$ can be confidently interpreted as a primary recorder of the $\delta \mathrm{D}$ of precipitation across the timeframe of interest here. Nevertheless, our interpretation of the climatic meaning of the $\delta \mathrm{D}_{\text {wax }}$ data is deliberately carried out through tandem use of the existing speleothem and foraminiferal $\delta^{18} \mathrm{O}$ data and isotope-enabled modeling experiments.

\subsection{Model Simulations}

[7] We obtained simulated precipitation fields from the pre-industrial control $(0 \mathrm{~K})$ and mid-Holocene $(6 \mathrm{~K})$ experiments conducted as part of the Paleoclimate Intercomparison Project 2 (PMIP2) [Braconnot et al., 2007] from all available fully coupled OAGCM models archived in the PMIP2 database, which includes CSIRO-MkL1.1, IPSL-CM4, CCSM3.0, FGOALS-g1.0, MIROC3.2, FOAM, MRI-CGCM2.3.4fa, MRI-CGCM2.3.4nfa, GISS ModelE-R, ECHAM5-MPI, and HadCM3M2. The mid-Holocene experiments were forced with orbitally induced changes in solar insolation as well as greenhouse gases estimated from ice core data. Details of the models and the parameters used for the PMIP2 modeling experiments are available online at http://pmip2.lsce.ipsl.fr. We also use precipitation and hydrogen and oxygen isotopes of precipitation fields from time slice simulations conducted with one of the PMIP2 models, the isotope-enabled GISS ModelE-R. Time slice simulations were conducted for $9 \mathrm{~K}$, and then every $1 \mathrm{~K}$ from $6-0 \mathrm{~K}$. Similar to the PMIP2 protocol, these experiments were forced with insolation changes and greenhouse gases. The 9K GISS time slice simulation incorporates a remnant Laurentide ice sheet, with mean ocean salinity and $\delta^{18} \mathrm{O}$ adjusted to account for the associated ice volume changes ( $35 \mathrm{psu},+0.33 \%$, equivalent to 35 meters of sea level change). Further details of the model, parameters used for the time slice simulations, as well as global results are described in LeGrande and Schmidt [2009].

[8] Though the sites of interest to this study (Borneo, Sulawesi, and Flores) are geographically close to one another (Figure 1), they experience different seasonal cycles in precipitation. GISS ModelE-R and the multimodel mean, respectively, reasonably approximate the distinct seasonal cycle of precipitation at these locales (Figure 2). This suggests that in spite of the relatively low spatial resolution of the PMIP2 OAGCMs, we can use the results of these simulations to investigate hydroclimate in this region with some confidence.

\section{Results and Discussion}

[9] The $\delta \mathrm{D}_{\text {wax }}$ data from core $70 \mathrm{GGC}$ are relatively enriched $(-155 \%)$ near $15,000 \mathrm{yr} \mathrm{BP}$, then trend toward more depleted values $(-170 \%$ ) until ca. 8,000 yr BP, after which they stabilize (Figure 3a). Higher-frequency variability punctuates the $\delta \mathrm{D}_{\text {wax }}$ record throughout, including an enrichment event at $\sim 900 \mathrm{yr}$ BP during the Medieval Climate Anomaly (MCA) that replicates the result of Tierney et al. [2010]. The data also show abrupt depletion around $11 \mathrm{ka}$, sustained depletion near $4 \mathrm{ka}$, and an enrichment event at $3 \mathrm{ka}$ 


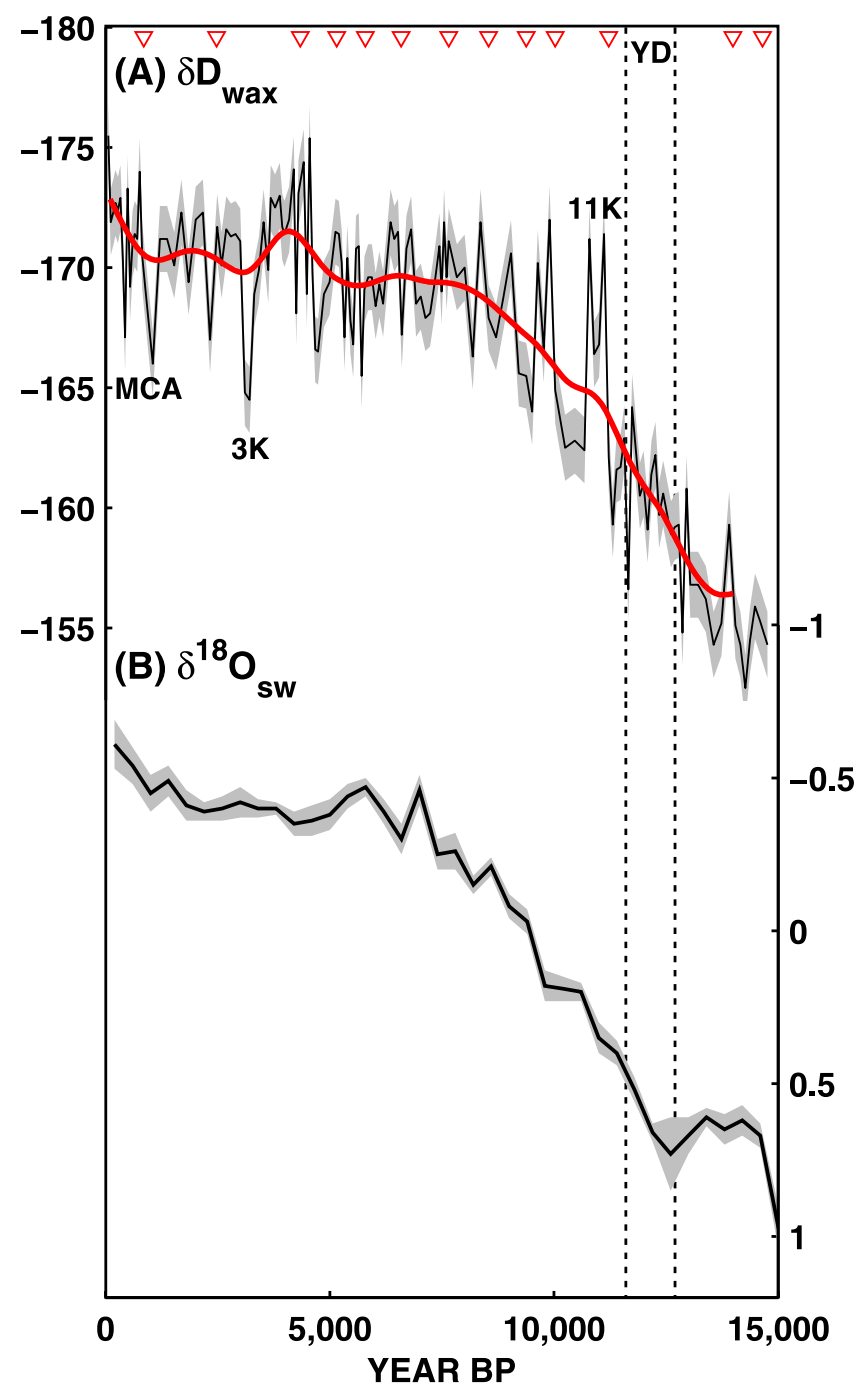

Figure 3. (a) Leaf wax hydrogen isotope data $\left(\delta \mathrm{D}_{\text {wax }}\right)$ from marine sediment core 70GGC. Gray error bars represent the analytical $95 \%$ confidence intervals. Red line represents a 500 -yr gaussian smoothing of the data to emphasize longterm trends.Red triangles indicate the stratigraphic locations of ${ }^{14} \mathrm{C}$ dates (Table 1). MCA marks the Medieval Climate Anomaly and an enrichment event that replicates the result of Tierney et al. [2010]. Dotted lines mark the beginning and end of the Younger Dryas chronozone (YD), when no change in Sulawesi $\delta \mathrm{D}_{\text {wax }}$ is observed. Other notable enrichment and depletion events as described in the main text are indicated. (b) Makassar Strait $\delta^{18} \mathrm{O}_{s w}$, reconstructed from paired foraminiferal $\mathrm{Mg} / \mathrm{Ca}$ and $\delta^{18} \mathrm{O}$ measurements in several marine sediment cores including 70GGC [Linsley et al., 2010]. Gray error bars represent the compounded analytical and core-compositing uncertainty.

(Figure 3a). There is no anomaly in $\delta \mathrm{D}_{\text {wax }}$ associated with the Younger Dryas (YD) event, similar to the speleothem $\delta^{18} \mathrm{O}$ data from Borneo [Partin et al., 2007], but unlike the speleothem $\delta^{18} \mathrm{O}$ record from Flores, which show isotopic depletion during the YD [Griffiths et al., 2009].
[10] Comparison between $\delta \mathrm{D}_{\text {wax }}$ and a reconstruction of seawater $\delta^{18} \mathrm{O}\left(\delta^{18} \mathrm{O}_{s w}\right)$ from the Makassar Strait (Figure 3b) indicates that both isotopic proxy records evolve similarly, with a linear trend toward isotopic depletion from 15-8 ka followed by relative stability during the rest of the Holocene. The 15-8 ka trend integrates several influences on IPWP water isotopic composition, including changes in global ice volume, regional temperature, oceanic and atmospheric advection of fresh water into and out of the IPWP, and local rainfall amount. SST proxy data suggest that regional temperatures rose ca. $1.5^{\circ} \mathrm{C}$ across this time interval [Linsley et al., 2010], which would only induce a minor (ca. 1.5\% for $\delta \mathrm{D}, 0.19 \%$ for $\delta^{18} \mathrm{O}$ ) [Majoube, 1971] change in the isotopic composition of rainfall, and ice volume can only account for an additional ca. $4 \%$ and $0.5 \%$ for $\delta \mathrm{D}$ and $\delta^{18} \mathrm{O}$, respectively (scaling inferred sea level changes to a glacial ocean enrichment of 1\%o) [Schrag et al., 1996]. Thus, the remaining ca. $9 \%$ o $(0.7 \%$ o) change between 14 and $8 \mathrm{ka}$ in the Sulawesi $\delta \mathrm{D}_{\text {wax }}\left(\delta^{18} \mathrm{O}_{s w}\right)$ record represents regional hydrological change. Seawater enrichment in the IPWP during the deglaciation and early Holocene is a robust feature of $\delta^{18} \mathrm{O}_{s w}$ proxy records from the region [Stott et al., 2004; Oppo et al., 2007; Linsley et al., 2010] and has been explained by increased export of water vapor to the Asian continent and Indian Ocean as a result of an intensified monsoon, an increase in the advection of salty waters from the central Pacific, and reduced transport of water vapor across the Panama isthmus [Oppo et al., 2007; LeGrande and Schmidt, 2011]. The isotopic enrichment may also reflect a reduction in regional rainfall amount. Previous GISS ModelE$\mathrm{R}$ isotope-enabled simulations [Lewis et al., 2010] identified rainfall amount as the climate parameter best correlated with precipitation isotopic variability in the Indonesian archipelago, and the timeslice simulations from GISS ModelE-R used here indicate that mean annual changes in precipitation amount and precipitation isotopes over Sulawesi during the Holocene (excluding 9K due to the simulated impact of ice volume) are strongly correlated $(r=0.94)$. Thus, the $15-8 \mathrm{ka}$ trend in the Sulawesi $\delta \mathrm{D}_{\text {wax }}$ data in particular likely reflects a shift from a drier deglacial period to wetter conditions during the Holocene. The simplest explanation for a dry deglacial period is a thermodynamic one (cooler temperatures cause reduced humidity and precipitation in the wet tropics) [e.g., Clement et al., 2004], but exposure of the Sunda Shelf may have promoted more severe regional divergence and drying [DiNezio et al., 2011].

[11] The absence of a trend from 8-0 ka in Sulawesi $\delta \mathrm{D}_{\text {wax }}$ suggests that changes in the seasonal distribution of insolation (i.e., orbital precession) had little apparent effect on the isotopes of precipitation at this location and that meridional movement of the ITCZ - oft-invoked to explain rainfall isotopic evolution elsewhere in the tropics on this timescale [Burns, 2011] - is not relevant for this sector of the deep tropics. Likewise, speleothem $\delta^{18} \mathrm{O}$ records from Borneo and Flores depict a complex time-evolution of IPWP water isotopes not immediately evocative of precessional influence (Figure 4). Like Sulawesi $\delta \mathrm{D}_{\text {wax }}$, these records show a trend from 15-8 ka, which suggests that deglacial forcings (changing ice volume, exposure of the Sunda Shelf) affected water isotopes uniformly across the Indonesian region. Yet 


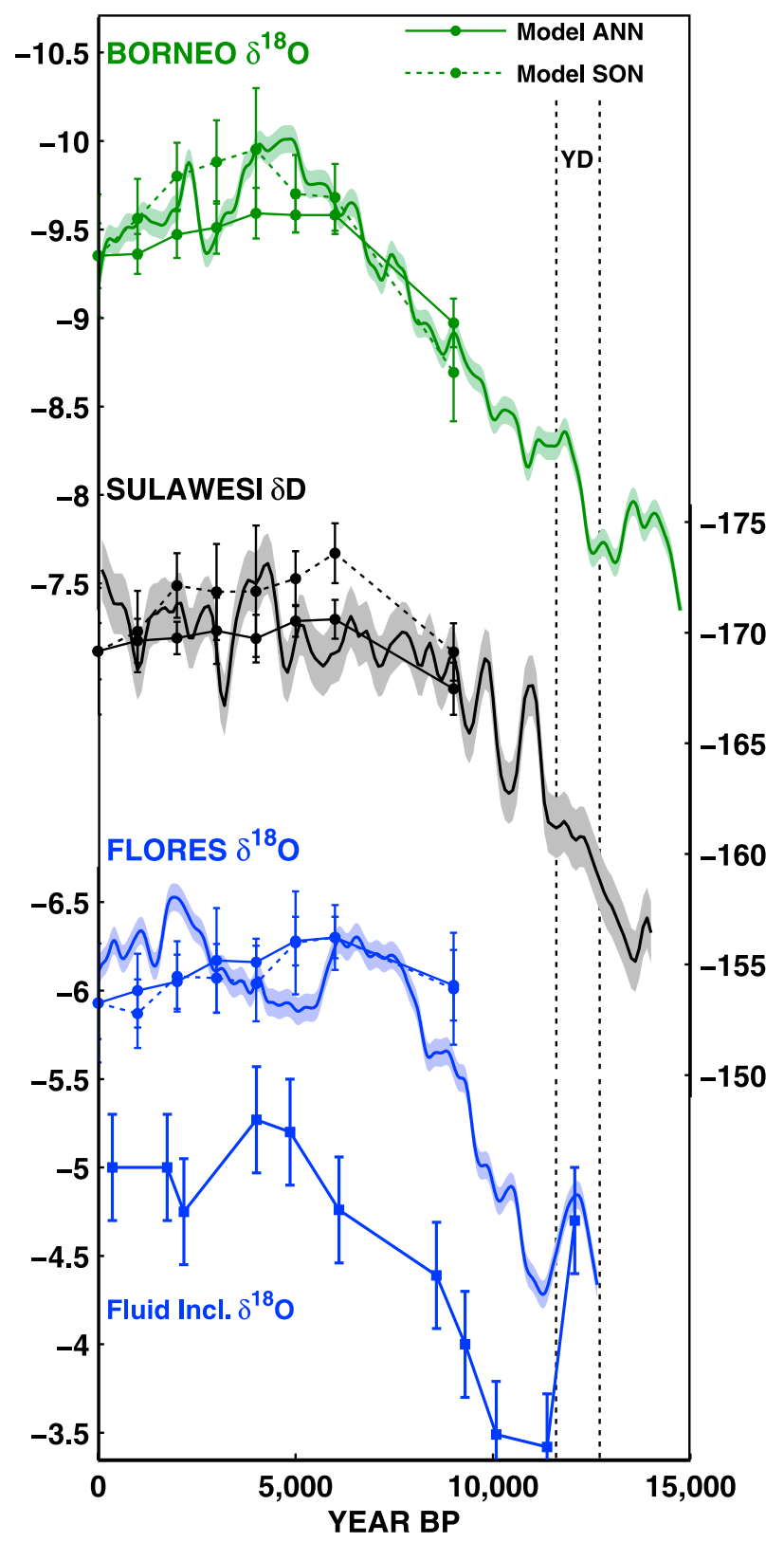

Figure 4. Simulated and proxy-reconstructed isotopic data from the IPWP (Partin et al. [2007], Griffiths et al. [2009, $2010 \mathrm{~b}$ ] and this study). Calcite $\delta^{18} \mathrm{O}$ and $\delta \mathrm{D}_{\text {wax }}$ data are plotted as 100-year gaussian-smoothed series to emphasize lower frequency variability, with analytical $95 \%$ confidence intervals. Fluid inclusion data from Flores [Griffiths et al., 2010 b] are plotted with $1 \sigma$ analytical error bars. Data are uncorrected for ice volume effects to facilitate comparison with the GISS ModelE-R timeslice results. Mean annual (solid lines) and SON (dotted lines) simulated precipitation isotopes from the GISS ModelE-R timeslice experiments are plotted on top of the proxy data; error bars indicate the $1 \sigma$ variation in the decadal means. For simulated isotopic values we show the precipitation-weighted mean $\delta^{18} \mathrm{O}$ or $\delta \mathrm{D}$ value from the same spatial boxes defined in Figure 2, normalized to the Holocene proxy mean for visual clarity. The anomalies in the proxy and model data are comparable. Dotted lines denote the Younger Dryas (YD) as in Figure 3. after $8 \mathrm{ka}$, the records diverge. At Borneo, the monotonic trend in $\delta^{18} \mathrm{O}$ continues until $4 \mathrm{ka}$ with a change in $\delta^{18} \mathrm{O}$ between $10-4 \mathrm{ka}$ of $\sim 1.5 \%$ o (Figure 4). In contrast, the $\delta^{18} \mathrm{O}$ record from Flores shows millennial-scale oscillations during the Holocene and more enriched $\delta^{18} \mathrm{O}$ near 4 ka (Figure 4).

[12] In addition to calcite $\delta^{18} \mathrm{O}$, Griffiths et al. [2010b] measured the $\delta^{18} \mathrm{O}$ of fluid inclusions within the Flores speleothem, which is presumably representative of the isotopic composition of the source water from which the calcite precipitated (Figure 4). While fluid inclusion $\delta^{18} \mathrm{O}$ shares the deglacial trend with the calcite $\delta^{18} \mathrm{O}$, its evolution is different during the Holocene in that it indicates more depleted values at $4-5 \mathrm{ka}$. The difference between calcite $\delta^{18} \mathrm{O}$ and inclusion $\delta^{18} \mathrm{O}$ may reflect the effect of changing cave temperatures on the fractionation between drip water and calcite. During the mid-Holocene, this difference is $0.7 \%$, which would theoretically imply that temperatures in the Flores cave were $\sim 3^{\circ} \mathrm{C}$ colder than present [Griffiths et al., 2010b]. This possible temperature effect is significant in the context of the $1 \%$ variability in Holocene calcite $\delta^{18} \mathrm{O}$. (Figure 4). Although the errors on the fluid inclusion measurements are large (Figure 4) and thus allow for a wide range in possible cave temperature estimates, these data present a possibility that cave temperatures influenced Flores calcite $\delta^{18} \mathrm{O}$ significantly, independent of rainfall $\delta^{18} \mathrm{O}$. Given this possibility along with the lack of replication of the record in a different cave, our conservative interpretation of the $\delta^{18} \mathrm{O}$ data from the Flores is that they do not resolve a mean change in local rainfall $\delta^{18} \mathrm{O}$ across the Holocene. In this sense, the Flores data are in rough agreement with the $\delta \mathrm{D}_{\text {wax }}$ data from Sulawesi. While cave temperatures could have influenced the Borneo record as well, unlike Flores the Borneo data were replicated in different caves $5 \mathrm{~km}$ apart [Partin et al., 2007]. A temperature overprint would thus require coordinated temperature variability between caves, presumably dictated by large changes in air temperatures. As SST proxy data suggest that temperatures were relatively stable in the IPWP across the Holocene [Linsley et al., 2010], this seems unlikely. In sum, the Holocene IPWP proxy isotopic data suggest peak depletion in $\delta^{18} \mathrm{O}$ at Borneo from 4-5 ka, but no detectable change in the mean isotopic composition of rainfall at Sulawesi and Flores.

[13] If we accept that the differences between the proxy data sites are correct, the question then arises, why are the water isotope data different between these sites? We turn to simulations of IPWP hydroclimate in coupled OAGCMs to seek answers. First, we use the GISS ModelE-R timeslice simulations to directly compare simulated water isotopes with the proxy data (Figure 4). Weighted mean annual precipitation isotopes are enriched at $9 \mathrm{~K}$ relative to $0 \mathrm{~K}$ but then change little across the rest of the Holocene at all three sites, in general agreement with the proxy data at Sulawesi and Flores, but not at Borneo. Rather, calcite $\delta^{18} \mathrm{O}$ at Borneo shows a better match with the simulated $\mathrm{SON}$-season oxygen isotopic composition of precipitation $\left(\delta^{18} \mathrm{O}_{p}\right)$, both of which show maximum depletion at $4 \mathrm{ka}$ (Figure 4 ). An observational study of the seasonal cycle of isotopes in precipitation in northern Borneo found that the time of maximum depletion in precipitation isotopes occurs during SON, when much of the water vapor originates from more remote southeasterly sources [Cobb et al., 2007]. Thus, rainfall variability during SON can strongly influence weighted mean-annual $\delta^{18} \mathrm{O}_{p}$. GISS 


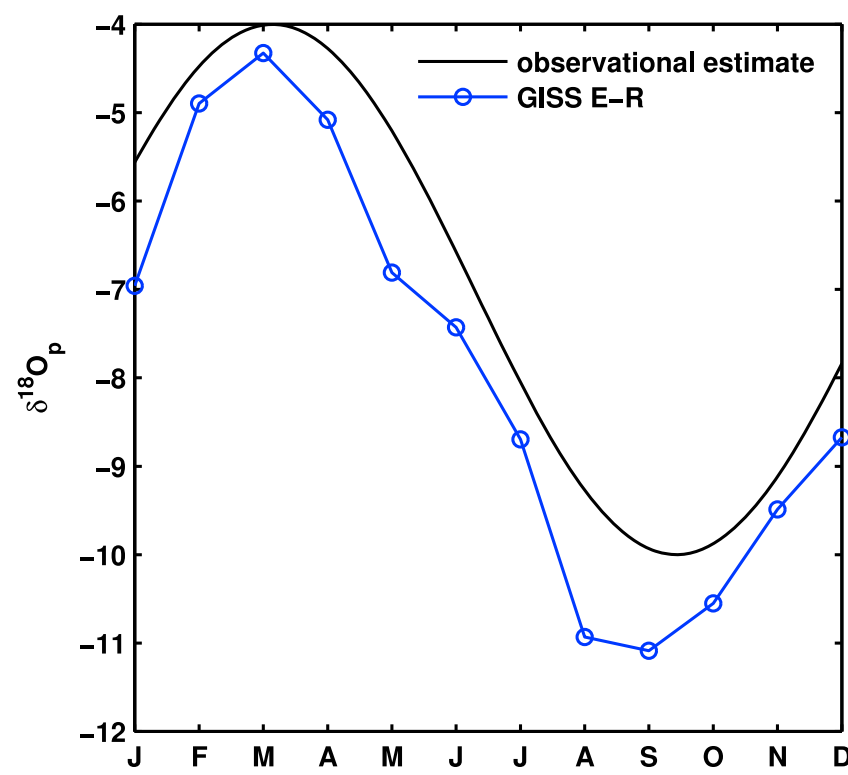

Figure 5. Comparison between an ad-hoc estimation of the seasonal cycle in precipitation $\delta^{18} \mathrm{O}\left(\delta^{18} \mathrm{O}_{p}\right)$ in northern Borneo, based on a three-year time series of observed rainwater and dripwater $\delta^{18} \mathrm{O}$ (black) [from Cobb et al., 2007] and the simulated seasonal cycle in $\delta^{18} \mathrm{O}_{p}$ in northern Borneo by GISS ModelE-R (blue).

ModelE-R simulates this seasonal cycle in $\delta^{18} \mathrm{O}_{p}$ at Borneo remarkably well (Figure 5), and as is the case with the observational data [Cobb et al., 2007], simulated $\delta^{18} \mathrm{O}_{p}$ has only a weak correlation $(r=0.28)$ with the seasonal cycle in rainfall amount (in contrast, simulated precipitation and $\delta^{18} \mathrm{O}_{p}$ are strongly correlated at both the Sulawesi and Flores sites, $r=0.84$ and $r=0.92$, respectively). The mismatch between simulated mean annual $\delta^{18} \mathrm{O}_{p}$ and proxy $\delta^{18} \mathrm{O}$ at Borneo, then, does not reflect a fundamental deficiency in the model, but rather may simply indicate that the model is underestimating the amount of SON rainfall at $4 \mathrm{~K}$ and/or the contribution of water vapor from the southeasterly source. Regardless, the depletion at $4 \mathrm{ka}$ (Figure 4) seen only in the Borneo proxy record suggests a hydroclimatic response that is seasonal in nature and primarily affects the Borneo landmass and immediate vicinity.

[14] What mechanisms might cause a unique hydroclimatic response in Borneo? Though we do not have multimodel simulations specifically at $4 \mathrm{ka}$, the multimodel mean of $6 \mathrm{~K}$ precipitation simulated by $11 \mathrm{OAGCMs}$ participating in PMIP2 (which includes GISS ModelE-R) yields insight into robust seasonal changes in mid-Holocene IPWP climate that may partially explain the heterogeneity in the proxy data. On a mean annual basis, the simulated changes in precipitation at $6 \mathrm{~K}$ relative to $0 \mathrm{~K}$ are close to zero $(+0.1 \mathrm{~mm} /$ day, $6 \mathrm{~K}-0 \mathrm{~K})$, in general agreement with the proxy isotopic data specifically at $6 \mathrm{~K}$ (Figure 4). However, on a seasonal basis there is a heterogenous response of hydroclimate to mid-Holocene climate conditions between Borneo, Sulawesi, and Flores (Figure 6). In boreal summer (June-July-August, JJA), precipitation increases at $6 \mathrm{~K}$ relative to $0 \mathrm{~K}$ over large landmasses in central Indonesia, causing wetter conditions over Borneo and Sumatra. In contrast, Sulawesi and Flores experience little change. Conversely, in boreal winter (December-JanuaryFebruary, DJF) precipitation decreases over all large land
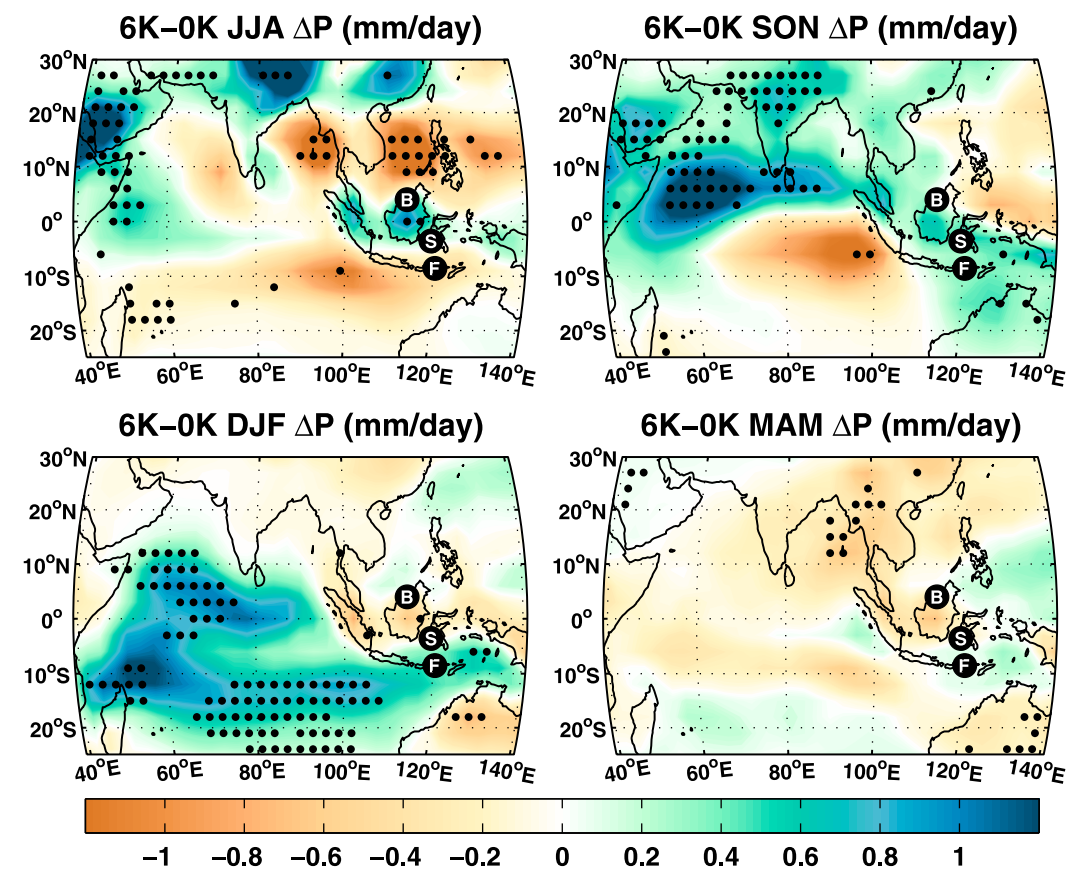

Figure 6. Multimodel mean of seasonal changes precipitation for the mid-Holocene (6K) relative to the preindustrial control (0K), as simulated by 11 PMIP2 OAGCMs: CSIRO-MkL1.1, IPSL-CM4, CCSM3.0, FGOALS-g1.0, MIROC3.2, FOAM, MRI-CGCM2.3.4fa, MRI-CGCM2.3.4nfa, GISS ModelE-R, ECHAM5-MPI, and HadCM3M2. B, S, and F = locations of the Borneo, Sulawesi, and Flores proxy isotope data. Stippling indicates regions where all 11 models agree on the sign of change. 

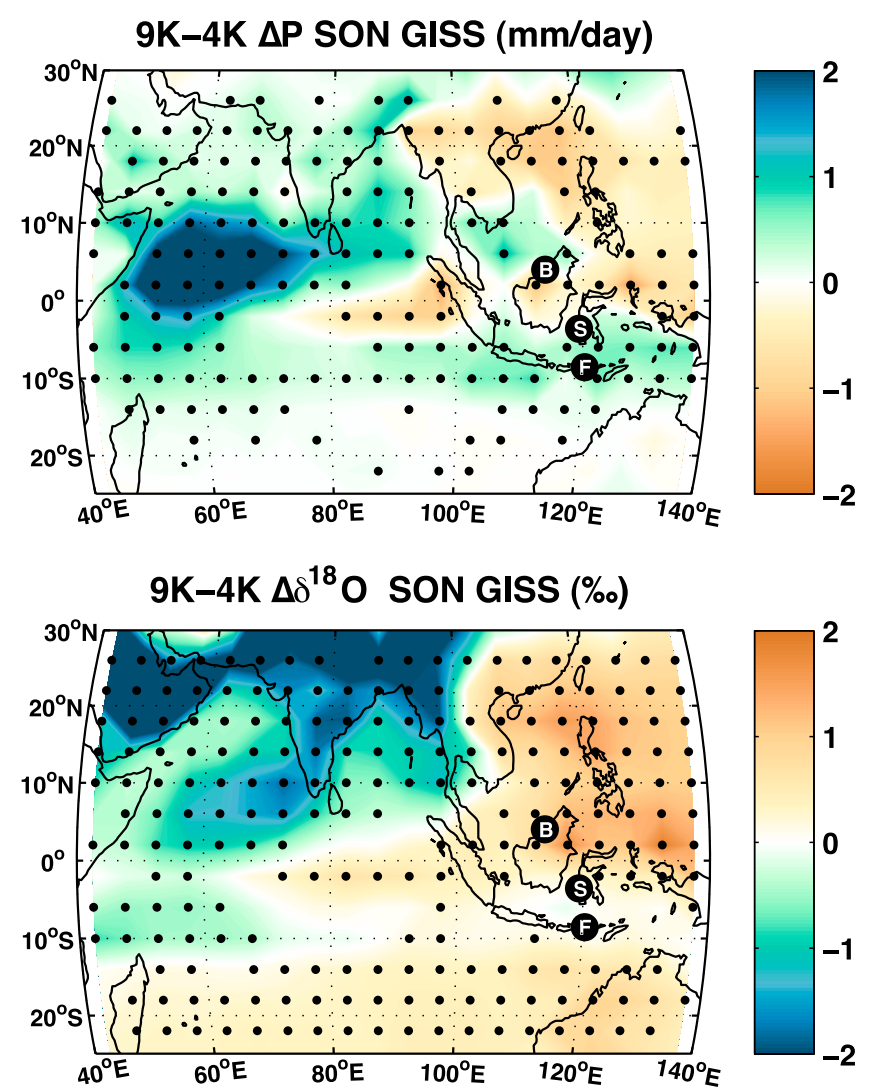

Figure 7. The $9 \mathrm{~K}$ versus $4 \mathrm{~K}$ anomalies in precipitation and the oxygen isotopes of precipitation simulated by GISS ModelE-R. Stippling indicates significant $(p<0.05)$ changes based on comparison with average decadal variability. B, S, and $\mathrm{F}=$ locations of the Borneo, Sulawesi, and Flores proxy isotope data.

surfaces in the IPWP - both north and south of the equator and increases over the Indian ocean (Figure 6). Flores, as a small island, experiences slightly wetter conditions during this season as precipitation shifts from land to sea, whereas Borneo is slightly drier. Generally speaking, the seasonal redistribution of precipitation at $6 \mathrm{~K}$ in the Indo-Pacific shows little meridional structure; rather, the changes in precipitation are from land to sea and vice versa. This reflects a differential influence of enhanced insolation seasonality, wherein increased insolation during the JJA season at $6 \mathrm{~K}$ heats landmasses faster relative to the ocean, enhancing monsoonal circulation throughout the northern hemisphere and in the equatorial tropics, and decreased insolation during the DJF season at $6 \mathrm{~K}$ cools land faster, resulting in divergence and enhanced export of moisture to areas over the ocean near the major landmasses [Liu et al., 2004; Clement et al., 2004; Zhao et al., 2005].

[15] These model results suggest that Borneo's unique hydroclimatic history could partially reflect the fact that the island is a large enough landmass to respond to temperaturedriven changes in seasonal convection in-phase with the other landmasses in the IPWP. However, if the JJA season dominated annual-mean $\delta^{18} \mathrm{O}_{p}$ at Borneo (as it arguably did on mainland Asia) [Wang et al., 2005], we might expect that Borneo $\delta^{18} \mathrm{O}$ would show peak depletion near 11-9 ka, when orbital configuration results in perihelion during JJA. Yet both the proxy $\delta^{18} \mathrm{O}$ and simulated $\delta^{18} \mathrm{O}$ from GISS ModelE-R suggest maximum depletion at $4 \mathrm{~K}$ and not $9 \mathrm{~K}$. The $4 \mathrm{ka}$ minimum may reflect a direct influence of increased insolation during the SON season (orbital configuration puts perihelion near SON at $4 \mathrm{ka}$ ), as Partin et al. [2007] hypothesized. Here we explicitly test that hypothesis by comparing the $9 \mathrm{~K}$ and $4 \mathrm{~K}$ results from the GISS ModelE-R timeslice experiments. We find that indeed, precipitation amount is somewhat reduced over Borneo at $9 \mathrm{~K}$ relative to $4 \mathrm{~K}$ in the GISS ModelE-R simulations and that the isotopic composition of rainfall is enriched by ca. 1\%o (Figure 7). The latter anomaly is in excellent agreement with the proxy data (Figure 4), but is larger then expected from the amount effect alone, implying less rain derived from the remote southeasterly source and possibly weaker convection at $9 \mathrm{~K}$ relative to $4 \mathrm{~K}$. However, there is no indication that the drying over Borneo at $9 \mathrm{~K}$ relative to $4 \mathrm{~K}$ during SON was caused by cooling associated with the change in seasonal insolation; there is a negligible anomaly in surface air temperature $\left(\triangle \mathrm{SAT} 9 \mathrm{~K}-4 \mathrm{~K}=-0.02^{\circ} \mathrm{C}\right)$.

[16] Alternatively, we argue that the timing of peak depletion in $\delta^{18} \mathrm{O}$ at Borneo at $4 \mathrm{~K}$ can be explained in part by large-scale changes in Walker circulation across the Indian Ocean basin. In the 6K PMIP2 simulations, there is a zonal redistribution of precipitation across the Indian Ocean basin during SON, with an increase in precipitation over the western Indian Ocean and a decrease over the eastern Indian Ocean off of Sumatra (Figure 6). This anomaly and the mechanisms that cause it have been discussed in the literature previously [Zhao et al., 2005; Tierney et al., 2011]. Tierney et al. [2011] argued that the change in convection is a seasonally lagged effect of Indian monsoon circulation on the western Indian Ocean heat budget. In JJA, the Indian monsoon winds are shifted northward during the early to mid-Holocene, reducing latent heat export out of the western Indian Ocean. This feeds the development of a warm SST anomaly several months later, which triggers an atmospheric response resulting in increased convection and rainfall in the western Indian Ocean, at the expense of divergence and drying in the eastern Indian Ocean in the ascending branch of the Walker cell. The effect of this mechanism on the hydrological cycle in the Indian Ocean is large and robustly simulated by different models (Figure 6). The zonal pattern of anomalies in precipitation and the isotopes of precipitation at $9 \mathrm{~K}$ relative to $4 \mathrm{~K}$ in GISS ModelE- $\mathrm{R}$ suggests that this mechanism is stronger in the early Holocene than at $4 \mathrm{ka}$ (Figure 7), as might be expected as it is related to the position and strength of the Indian monsoonal winds during boreal summer (which are stronger/farther north at $9 \mathrm{~K}$ ). Upper-level $(250 \mathrm{mb})$ zonal westerly anomalies between $9 \mathrm{~K}$ and $4 \mathrm{~K}(0.9 \mathrm{~m} / \mathrm{s})$ and easterly zonal surface wind anomalies $(-0.6 \mathrm{~m} / \mathrm{s})$ further suggest that there is a relative weakening in Indian Ocean Walker circulation at $9 \mathrm{~K}$ during SON.

[17] Given these results, we hypothesize that the observed trend in Borneo hydroclimate across the Holocene reflects a balance between two competing mechanisms: the direct effect that JJA perihelion has on precipitation due to heating and convection, and the indirect effect that JJA perihelion 
has on coupled ocean-atmosphere dynamics during SON. In the early Holocene, the latter mechanism dominates, whereas in the mid-Holocene, the former mechanism dominates, resulting in maximum isotopic depletion at a point of compromise around $4 \mathrm{ka}$. Both of these mechanisms are less important for hydroclimate at Flores and Sulawesi, which do not experience increased precipitation during JJA (Figure 6), and - if the GISS results are a robust indication - sit outside the core of the isotopic anomaly associated with weaker Indian Walker circulation (Figure 7).

\section{Conclusions}

[18] Our investigation of model and proxy evidence for changes in IPWP hydroclimate during the Holocene reveals that IPWP response to orbitally induced changes in insolation is heterogenous across the region on the seasonal level, and thus differences in hydroclimatic evolution between Borneo and central Indonesia are expected. The Sulawesi site in particular sits near the zero line of most of the seasonal anomalies (Figure 6) and so the new proxy $\delta \mathrm{D}_{\text {wax }}$ data we present here - which imply little change in mean $\delta \mathrm{D}$ of precipitation across the Holocene - are in good agreement with the model simulations. As temperature changes complicate the interpretation of Flores calcite $\delta^{18} \mathrm{O}$, we cannot robustly determine whether the model simulations agree with the proxy data. At Borneo, we find excellent agreement between the $\delta^{18} \mathrm{O}$ proxy data and simulated SON $\delta^{18} \mathrm{O}$ of precipitation in GISS ModelE-R, and the Borneo site is uniquely sensitive to large-scale changes in IPWP hydrology that occur during this season. The development of longer proxy isotopic records from Borneo and the vicinity will be an important test of our hypothesis that two competing mechanisms - both related to Indian Ocean atmospheric circulation - influence Borneo hydroclimate on precessional timescales.

[19] Acknowledgments. We would like to thank T. Koutavas, E. Schefuß, and two anonymous reviewers for discussion and comments that have greatly improved the manuscript. We thank R. Tarozo at Brown University for assistance with the $\delta \mathrm{D}_{\text {wax }}$ analyses. We thank the climate modeling groups participating in PMIP2 for providing their data for this analysis, and the PMIP2 Data Archive (supported by CEA, CNRS, and PNEDC) for distributing the data. The analyses were performed using version 02-082012 of the PMIP2 database. J. Tierney acknowledges the NOAA Climate and Global Change Postdoctoral Fellowship for support.

\section{References}

Braconnot, P., et al. (2007), Results of PMIP2 coupled simulations of the Mid-Holocene and Last Glacial Maximum-Part 1: Experiments and large-scale features, Clim. Past, 3(2), 261-277.

Burns, S. (2011), Speleothem records of changes in tropical hydrology over the Holocene and possible implications for atmospheric methane, Holocene, 21(5), 735-741.

Clement, A., A. Hall, and A. Broccoli (2004), The importance of precessional signals in the tropical climate, Clim. Dyn., 22(4), 327-341.

Cobb, K. M., J. F. Adkins, J. W. Partin, and B. Clark (2007), Regional-scale climate influences on temporal variations of rainwater and cave dripwater oxygen isotopes in northern Borneo, Earth Planet. Sci. Lett., 263(3-4), 207-220, doi:10.1016/j.eps1.2007.08.024.

Dam, R. A. C., J. Fluin, P. Suparan, and S. van der Kaars (2001), Palaeoenvironmental developments in the Lake Tondano area (N. Sulawesi, Indonesia) since 33,000 yr BP, Palaeogeogr. Palaeoclimatol. Palaeoecol., 171, $147-183$.

DiNezio, P., A. Clement, and G. Vecchi (2010), Reconciling differing views of tropical Pacific climate change, Eos Trans. $A G U, 91(16), 141-142$.
DiNezio, P., A. Clement, G. Vecchi, B. Soden, A. Broccoli, B. Otto-Bliesner, and P. Braconnot (2011), The response of the Walker circulation to Last Glacial Maximum forcing: Implications for detection in proxies, Paleoceanography, 26, PA3217, doi:10.1029/2010PA002083.

Gibbons, F. (2012), The centennial and millennial variability of the IndoPacific Warm Pool and the Indonesian Throughflow, PhD thesis, Woods Hole Oceanogr. Inst., Woods Hole, Mass.

Griffiths, M. L., et al. (2009), Increasing Australian-Indonesian monsoon rainfall linked to early Holocene sea-level rise, Nat. Geosci., 2(9), 636-639, doi:10.1038/NGEO605.

Griffiths, M., et al. (2010a), Evidence for Holocene changes in AustralianIndonesian monsoon rainfall from stalagmite trace element and stable isotope ratios, Earth Planet. Sci. Lett., 292(1-2), 27-38.

Griffiths, M., et al. (2010b), Younger Dryas-Holocene temperature and rainfall history of southern Indonesia from $\delta^{18} \mathrm{O}$ in speleothem calcite and fluid inclusions, Earth Planet. Sci. Lett., 295(1), 30-36.

Karnauskas, K. B., R. Seager, A. Kaplan, Y. Kushnir, and M. A. Cane (2009), Observed strengthening of the zonal sea surface temperature gradient across the equatorial Pacific Ocean, J. Clim., 22(16), 4316-4321, doi:10.1175/2009JCLI2936.1.

LeGrande, A. N., and G. A. Schmidt (2009), Sources of Holocene variability of oxygen isotopes in paleoclimate archives, Clim. Past, 5(3), 441-455.

LeGrande, A. N., and G. A. Schmidt (2011), Water isotopologues as a quantitative paleosalinity proxy, Paleoceanography, 26, PA3225 doi:10.1029/2010PA002043.

Lewis, S. C., A. N. LeGrande, M. Kelley, and G. A. Schmidt (2010), Water vapour source impacts on oxygen isotope variability in tropical precipitation during Heinrich events, Clim. Past, 6(3), 325-343, doi:10.5194/cp-6325-2010.

Linsley, B., Y. Rosenthal, and D. Oppo (2010), Holocene evolution of the Indonesian throughflow and the western Pacific warm pool, Nat. Geosci., 3(8), 578-583.

Liu, Z., S. Harrison, J. Kutzbach, and B. Otto-Bliesner (2004), Global monsoons in the mid-Holocene and oceanic feedback, Clim. Dyn., 22(2), $157-182$.

Majoube, M. (1971), Fractionnement en oxygène-18 et en deutérium entre 1'eau at sa vapeur, J. Chem. Phys., 197, 1423-1436.

Oppo, D. W., G. A. Schmidt, and A. N. LeGrande (2007), Seawater isotope constraints on tropical hydrology during the Holocene, Geophys. Res. Lett., 34, L13701, doi:10.1029/2007GL030017.

Oppo, D. W., Y. Rosenthal, and B. K. Linsley (2009), 2,000-year-long temperature and hydrology reconstructions from the Indo-Pacific warm pool, Nature, 460(7259), 1113-1116, doi:10.1038/nature08233.

Partin, J. W., K. M. Cobb, J. F. Adkins, B. Clark, and D. P. Fernandez (2007), Millennial-scale trends in west Pacific warm pool hydrology since the Last Glacial Maximum, Nature, 449, 452-455, doi:10.1038/ nature06164.

Pausata, F., D. Battisti, K. Nisancioglu, and C. Bitz (2011), Chinese stalagmite $\delta^{18} \mathrm{O}$ controlled by changes in the Indian monsoon during a simulated Heinrich event, Nat. Geosci., 4(7), 474-480.

Reimer, P. J., et al. (2009), IntCal09 and Marine09 radiocarbon age calibration curves, 0-50,000 years Cal BP, Radiocarbon, 51(4), 1111-1150.

Ropelewski, C., and M. Halpert (1987), Global and regional scale precipitation patterns associated with the El Niño/Southern Oscillation, Mon. Weather Rev., 115(8), 1606-1626.

Rudolf, B., A. Becker, U. Schneider, A. Meyer-Christoffer, and M. Ziese (2011), GPCC status report December 2011, 7 pp., Global Precip. Climatol. Cent., Offenbach, Germany.

Sachse, D., et al. (2012), Molecular paleohydrology: Interpreting the hydrogen-isotopic composition of lipid biomarkers from photosynthesizing organisms, Annu. Rev. Earth Planet. Sci., 40, 221-249.

Schefuß, E., S. Schouten, and R. R. Schneider (2005), Climatic controls on central African hydrology during the past 20,000 years, Nature, 437(7061), 1003-1006, doi:10.1038/nature03945.

Schrag, D. P., G. Hampt, and D. W. Murray (1996), Pore fluid constraints on the temperature and oxygen isotopic composition of the glacial ocean, Science, 272, 1930-1932.

Stott, L. D., K. G. Cannariato, R. C. Thunell, G. H. Haug, A. Koutavas, and S. Lund (2004), Decline of surface temperature and salinity in the western tropical Pacific Ocean in the Holocene epoch, Nature, 431(7004), 56-59, doi:10.1038/nature02903.

Tierney, J. E., J. M. Russell, Y. Huang, J. S. Sinninghe Damsté, E. C. Hopmans, and A. S. Cohen (2008), Northern Hemisphere controls on tropical southeast African climate during the past 60,000 years, Science, 322(5899), 252-255, doi:10.1126/science.1160485.

Tierney, J. E., D. W. Oppo, Y. Rosenthal, J. M. Russell, and B. K. Linsley (2010), Coordinated hydrological regimes in the Indo-Pacific region 
during the past two millennia, Paleoceanography, 25, PA1102, doi:10.1029/2009PA001871.

Tierney, J. E., S. C. Lewis, B. I. Cook, A. N. LeGrande, and G. A. Schmidt (2011), Model, proxy and isotopic perspectives on the East African Humid Period, Earth Planet. Sci. Lett., 307, 103-112, doi:10.1016/ j.epsl.2011.04.038.

Vecchi, G. A., B. J. Soden, A. T. Wittenberg, I. M. Held, A. Leetmaa, and M. J. Harrison (2006), Weakening of tropical Pacific atmospheric circulation due to anthropogenic forcing, Nature, 441(7089), 73-76, doi:10.1038/nature04744.

Wang, Y., et al. (2005), The Holocene Asian monsoon: Links to solar changes and North Atlantic climate, Science, 308(5723), 854-857, doi:10.1126/science.1106296.

Zhao, Y., et al. (2005), A multi-model analysis of the role of the ocean on the African and Indian monsoon during the mid-Holocene, Clim. Dyn., 25(7), 777-800. 